\title{
Preface to earlier book
}

Students tend to find micro-economics one of the more difficult parts of the subject [of economics]: they regard it as abstract, unrealistic, and remote from 'real-world' problems. This was our starting point. We believe that micro-economics as the study of choice is the foundation of the subject and that economists have an obligation to show students how micro-economics theory can be used and applied.

Applied micro-economics embraces empirical work and policy issues, and our emphasis is on the latter. This book avoids the presentation of micro-economic theory in a 'vacuum'. It shows students how micro-economics can be applied to major issues of public policy. In the process, it is hoped to improve the understanding of both microeconomic theory and policy.

Micro-economics consists of price theory and welfare economics, embracing theories of consumer and firm behaviour, the operation of product and factor markets, the role of the state, and the 'desirability' of policy changes. We have tried to show the policy relevance of each of the major components of micro-economic theory. However, the emphasis is on general principles of micro-economic policy, rather than on providing a detailed account of any one nation's actual policies. Indeed, the different nationalities and backgrounds of the authors has contributed to the development of a text suitable for an international audience. The book is written for students interested in the application of micro-economics to policy issues in capitalist-type economies. Throughout, the emphasis is on analysis rather than description.

The book is designed for late first year and second year [as well as later] higher education students who have a basic knowledge of micro-economic theory. The aim is to learn through applications in a policy context. While nations will differ in the extent and form of state intervention within product and factor markets, the examples chosen are typical of the policy issues confronting many governments. Hence, our emphasis is on the principles of micro-economic policy: the objective is to provide students with a general 'toolkit' which can be applied to any specific micro-policy problem.

In addition to applying standard theory, we have introduced students to some of the more recent developments in the subject. These include the economics of politics, bureaucracies, and public choice; the Austrian school of subjectivism; search behaviour among consumers and workers; the economics of population; managerial theories of the firm, multi-nationals, labour-managed firms, advertising, and regulation; employment contracts, human capital, and screening; energy and pollution; time-cost trade-offs, deindustrialization, and public sector micro-economics, including defence, alliances, nuclear weapons choices and the economics of conscription versus an all-volunteer force.

The book is divided into five parts. Part A considers how economists approach micropolicy issues and why governments need micro-economic policies, either as a means of contributing to society's welfare or to obtain votes. Part B is concerned with applications of demand, supply, and competitive market analysis. Imperfect markets, including models 
of firm behaviour, monopoly, and oligopoly are analysed in Part C. Factor markets in the form of labour, trade unions, and human capital markets are discussed in Part D, which concludes with a chapter on energy. Given the book's emphasis on public policy, it seemed appropriate to conclude with an analysis of the public sector (Part E). To assist students, each chapter has suggestions for further reading and there are questions for review and discussion.

Readers might be curious to know how the authors, located in Australia and England, could possibly have written a joint textbook. The enterprise was greatly facilitated by Clem Tisdell's visit to the United Kingdom when he spent the Autumn Term of 1979 located at the Institute of Social and Economic Research (ISER), the University of York. This allowed both authors to work together in planning, discussing, and writing each chapter, either in outline or in its first draft form. Each author was responsible for specific chapters and parts, but both commented and agreed on each other's chapters. We are indebted to Professor Jack Wiseman, ISER, for providing office accommodation, facilities, and an attractive research environment. John Hutton, Research Fellow at ISER, kindly read and commented on the manuscript. Others who have offered specific comments, contributions, and assistance, sometimes unknowingly, included Celia Bird, Michael Coombs, Tony Culyer, Douglas Dosser, Ted Lynk, Cecil Margolis, Alan Maynard, John Nash, Bernard O'Brien, Alan Peacock, Robin Shannon, and Alan Williams. Colleagues and students at the Universities of York and Newcastle, Australia, have always been willing teachers and listeners. Barbara Dodds, Elizabeth Williams, Wendy Amos-Binks, and Margaret Johnson had the unenviable task of typing their way through our handwriting. Finally, our families have been the victims of scarcity resulting from our writing. Our thanks to Winifred and Mariel for their patience, and to our children Adam, Lucy, Cecilia, together with AnnMarie and Christopher.

January, 1981

KEITH HARTLEY CLEM TISDELL 
Clem Tisdell and Keith Hartley - 9781848441514 Downloaded from PubFactory at 04/26/2023 07:24:39AM 